\title{
A Simulation Model of a School's Evacuation
}

\author{
Aleksandrs Korolko, Valdis Abrams, Natalja Kucerenko*, Dins Lolans
}

Riga Secondary School nr 80, Andromedas gate 11, 1084 Riga, Latvia; ${ }^{*}$ r80vs@riga.Iv

SNE 28(3), 2018, 133 - 135, DOI: 10.11128/sne.28.sn.10437

Received: Sept. 15, 2016 (Selected EUROSIM Congress 2016 Postconf. Publ.), Revised July 30, Accepted: August 25, 2018

SNE - Simulation Notes Europe, ARGESIM Publisher Vienna, ISSN Print 2305-9974, Online 2306-0271, www.sne-journal.org

Abstract. This research paper describes a simulation model that was implemented as an evacuation efficiency evaluation software tool. Currently, according to experts, evaluation of the evacuation schemes in Latvia is done based on field experiments. This has been shown to result in an inefficient allocation of human resources and interruption of the study process at school. Consequently, a simulation model for a school's evaluation was required that does not rely on field experimentation. Using (a) the data provided by the school's administration and (b) simulation modelling methodology, a decision support system for an evaluation of an evacuation process was developed and tested. This system supplies the school's administration with information about the problem areas in the current evacuation process. The simulation process results are analyzed in a data collection environment (graphs, diagrams, tables etc.) that was developed using the JAVA programming language. The hypothesis of a successful simulation model was tested applying the Mann-Whitney test and found to be credible. Based on the findings, a number of recommendations were developed for increasing the efficiency of the evacuation process in buildings sharing the layout of the school tested here. With necessary adjustments, the developed simulation model can be recommended for evaluating evacuation schemes in buildings with similar layouts, and possibly for implementation beyond Latvia.

\section{Introduction}

As a result of significant developments in computer science it has become easier to solve complex tasks, especially ones that require considerable time and financial investment. Among the most popular such developments is simulation modelling (SM).
Modelling means to replace the original object of research with a defined image or other object (model), studying the attributes of the original. The model is then deployed in experiments in the place of the original, delivering data about the research object [1]. The simulation modelling method is considered one of the most efficient methods in the study of complex systems, because "SM enables experimentation with real or applied systems, in instances when the real object is unavailable or its use is not desired" [2]. With the help of the agent based modelling (ABM) method, simulation modelling agents are able to independently evaluate situations, make decisions and act based on them according to the system settings [3].

In this instance, a simulation model was implemented as an evacuation process efficiency evaluation software tool. According to experts, the evaluation of the evacuation schemes in Latvia currently relies on field experiments. This includes the hospital, kindergarten, and school evacuation systems and leads to inefficient allocation of human resources and finances. Consequently, this scientific work attempted to solve the task of developing a decision making system serving as a simulation model of a school's evacuation. Its main function is to evaluate the efficiency of the evacuation process without interrupting the study process. This scientific work serves as a school-university partnership example. This partnership enables one to find a future university degree track and opens opportunities for scientific research already at the high school level.

\section{Methodological Foundation of the Scientific Research Work}

The theoretical section of this scientific research work includes an introduction to simulation modelling with an emphasis on agent based simulation (ABM); a comparison of various computer based simulation modelling systems; an overview of pertinent literature and sources; an overview of simulation modelling methodology; an analysis of AnyLogic simulation software. 
$\mathrm{ABM}$ is defined as follows: "Agent is an entity with an autonomous behaviour, able to make decisions based on given parameters, interact with the surrounding environment, and adapt to the changes therein" [4].

The following entities can act as agents: transport, devices, non-material objects, organizations and people (for example: children, students, teachers). The task of ABM simulation consists of: (a) defining the parameters of agents and the environment and (b) studying the agents' behaviour in various environments and interaction scenarios. By situating various agents in a defined space and within the corresponding interaction parameters, it is possible to predict the behaviour of the entire system [5].

As is known, the field of simulation modelling employs the following software (to name a few): GPSS, SYMULA, Arena, AutoMod, Enterprise Dynamics, FlexSim (in discrete event simulation); Net Logo, Swarm, Repast, ASCAPE, Extend (in agent based simulation); VenSim, PowerSim, AnyLogic, iSink (in system dynamic simulation). AnyLogic software, however, is applicable in all three types of simulation [6]. Based on a comparison of these simulation modelling systems it was concluded that the AnyLogic system offered the widest range of functions. Consequently, AnyLogic SM system was selected for the development of the simulation model in this scientific work.

\section{Development of a Simulation Model}

Based on the AnyLogic methodology, a simulation model was created for a school's evacuation. The model's development consisted of eight stages: designing the system structure with the help of the Pedestrian library; classifying the active objects; entering the standard block parameters; entering the additional parameters; designing the animation; calibrating the model; validating the model; experimental approbation of the finished model. The following data was supplied by the school's administration in order to make a validation of the model: school layout, evacuation schemes, number of students in each classroom, number of school staff, and evacuation times over three years of fire drills.

The development began with selecting an appropriate scale for an authentic reflection of the school's layout.
The AnyLogic agents were created along with algorithms of their behaviour (movement, decisions etc.) in emergency situations. A schematic algorithm was created connecting the evacuation paths for students with school emergency exits. The following standard block parameters were entered: Ped Source, Ped Go To, Ped Change Ground, Ped Group Assemble, Camera. Additional parameters included histograms timing the evacuation process, as well as a Java function (Last Exit) taking and depicting the time of the last agent's exit.

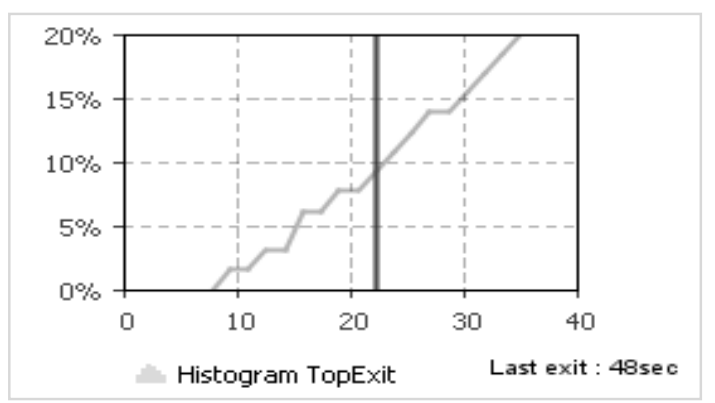

Figure 1. Simulation model activity histogram.

The 2D and 3D animation featured a special 3D log and a Camera object showing a fixed layout sector. A special program interface was created for expedited switching between floors, histograms and 3D model animation. Pedestrian library images were used to designate various members of the school personnel.

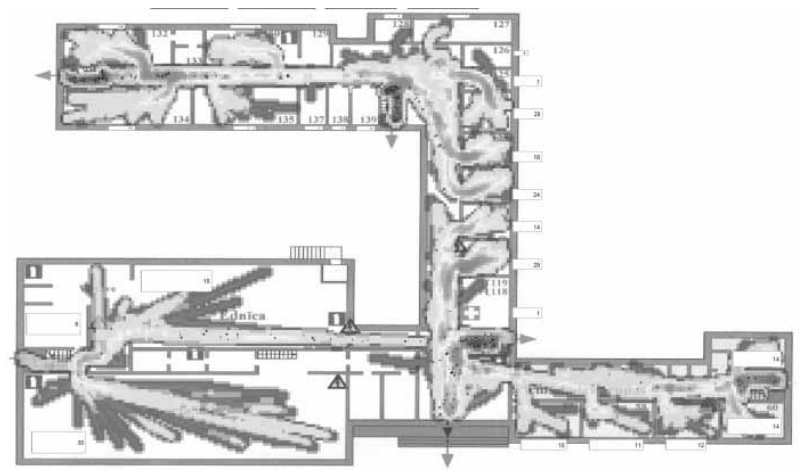

Figure 2. Simulation model animation in 2D.

A statistical hypothesis test was implemented applying the Mann-Whitney test. It confirmed the main hypothesis: data discrepancy between the model-based test and real data is not significant. The following MannWhitney U test was used:

$$
U=N M+\frac{N(N+1)}{2}-\sum_{x_{1}} \operatorname{Rank}\left(x_{i}\right)
$$

As a result, the simulation model (SM) was found to be credible. 


\section{Conclusion}

This scientific research work contains a simulation model for a school's evaluation that does not rely on field experimentation. The pertinent theory is studied and the existing approaches to simulation modelling (based on the ABM method) are surveyed. Various simulation software systems are compared and AnyLogic methodology is studied closely. Employing the AnyLogic system, in the practical section of the research work a decision support system is produced evaluating the efficiency of a school's evacuation and informing the school's administration about the problem areas in the evacuation process.

The model's flexibility and credibility allows for its easy adaptation not only in buildings with similar layouts in Latvia (for example: schools or kindergartens), but also abroad. The development's authors are open to partnership, plan to further optimize the model, and can offer recommendations and instructions for the model's implementation. This material reflects the scientific research work of M. Savrasov (Dr. Sc. Ing., Assistant professor), N. Kucerenko (Mag. Paed.), V. Zemlanikins (Tech. consultant).

\section{References}

[1] A.M. Law and W.D. Kelton, "Simulation ModelingModelling and Analysis. McGraw-Hill Series in Industrial Engineering and Management Science," 3rd ed. McGraw-Hill: New York, 2000, pp. 529-551.

[2] В.П. Строгалев, И.О. Толкачева, "Имитационное моделирование: Учеб. пособие.” МГТУ: Москва, 2008, 7 стр.

[3] E. Bonabeau. (2002). Agent-based modeling: Methods and techniques for simulating human systems [online]. Available: http://www.pnas.org/content/99/suppl_3/7280.full.pdf

[4] В. Маликов. (2013). Практикум по моделированию сложных систем в среде AnyLogic 6 [online]. Available: http://simulation.su/uploads/files/default/2013malikov-praktikum-anylogic-6.pdf

[5] AnyLogic Portal [online]. Available: http://www.anylogic.com/agent-based-modeling

[6] А. Г. Купряшкин. (2015). Основы моделирования систем [online]. Available : http://www.anylogic.ru/upload/pdf/osnovi_modelirovani a_sistem.pdf 